\title{
Análise do discurso e formação de professores de português como língua de acolhimento
}

\author{
Edmundo Narracci Gasparini ${ }^{1}$ \\ Hiago Higor de Lima
}

\begin{abstract}
Resumo: Neste ensaio, abordamos elementos da Análise do Discurso que podem contribuir para uma perspectiva crítica e decolonial na formação de professores de português como língua de acolhimento (PLAc). Procuramos dar destaque ao que há de discursivo no "acolhimento" aos deslocados forçados no âmbito do ensino e da aprendizagem de PLAc e, nessa direção, discutimos o discurso da falta (DINIZ; NEVES, 2018) e o discurso da obrigatoriedade da aprendizagem do português (LOPEZ, 2018). A retomada de elementos teóricos provenientes da Análise do Discurso possibilitou-nos identificar, em ambos os discursos, efeitos de sentido do discurso pedagógico (ORLANDI, 1996), no âmbito do qual se promove um "esmagamento do outro" em função de imagens socialmente cristalizadas do professor e do aluno. Vislumbramos a possibilidade de resistência e deslocamento em relação a ambos os discursos na medida em que, em oposição ao discurso pedagógico, se promova uma relação mais conflituosa entre professor de PLAc e aprendiz, a partir da qual se dá voz aos alunos e se garante a eles a possibilidade de discordância. Tal possibilidade de resistência e deslocamento, elaborada a partir dos pressupostos teóricos da Análise do Discurso, é um elemento que pode contribuir para a decolonialidade na formação de professores de PLAc.
\end{abstract}

Palavras-chave: Português Língua de Acolhimento, Formação de Professores, Análise do Discurso, Decolonialidade.

\footnotetext{
${ }^{1}$ Professor do Departamento de Letras, Artes e Cultura e do Programa de Pós-Graduação em Letras da UFSJ. Doutor em Linguística. Áreas de atuação: análise do discurso; ensino de língua estrangeira. E-mail: gaspar@ufsj.edu.br.

2 Mestrando no Programa de Pós-Graduação em Letras da UFSJ. E-mail: hiagohigor7@gmail.com.
} 


\section{Introdução}

O ensino e a aprendizagem de português como língua de acolhimento (PLAc) para sujeitos que passam por processos de migração forçada (CLOCHARD, 2007) têm representado um desafio no contexto brasileiro atual. Não há documentos oficiais que regulamentem o ensino para esse público (LOPEZ, 2016) e os materiais didáticos desenvolvidos especificamente para o grupo ainda são escassos (LIMA; VIANINI, 2019). Diferentes autores (DINIZ; NEVES, 2018; LOPEZ, 2018) referem-se também à carência de políticas públicas para o ensino e a aprendizagem de PLAc.

No que se refere à formação de professores de PLAc, os desafios não são menores: os professores, muitas vezes, não têm formação específica para trabalhar com imigrantes forçados (ou sequer têm habilitação/autorização para lecionar), sendo muito comum, ainda, que tal prática se dê de forma voluntária (AMADO, 2013; LOPEZ, 2016; ZAMBRANO, 2019). Ademais, o contexto de imersão no Brasil, atrelado a possíveis situações de desamparo (AYDOS, 2010) e vulnerabilidade (LOPEZ, 2016; SÃO BERNARDO, 2016), pode colocar o imigrante deslocado forçado demarcado por discursos preconceituosos que atravessam a prática de ensino e aprendizagem de PLAc. A existência de tais discursos confronta a formação do professor de PLAc com mais um desafio, apontando para a necessidade de formação específica na área.

Neste trabalho, pretendemos abordar elementos da Análise do Discurso elaborados por Michel Pêcheux (1997) e por Eni Orlandi (1996) que, segundo nossa leitura, podem contribuir para a construção de uma perspectiva crítica e decolonial na formação do professor de PLAc. Sentimo-nos convocados pela chamada para publicação neste número da Glauks, cujo foco é "Perspectivas críticas e decoloniais na formação de professores de línguas: avanços e desafios". Formulamos então uma pergunta, que foi norteadora do trajeto que percorremos aqui: a partir da Análise do Discurso, o que poderia ser um posicionamento "crítico" e

Gláuks: Revista de Letras e Artes-jan/jun. 2020 - Vol. 20, $N^{o} 1$ 
"decolonial" frente ao desafio de formar professores de português como língua de acolhimento? A escrita deste ensaio foi uma tentativa de formular uma resposta.

Iniciaremos nosso percurso delimitando a área do ensino e da aprendizagem de PLAc e identificando alguns desafios na formação do professor na área. Em seguida, discutiremos elementos teóricos formulados no âmbito da Análise do Discurso que, conforme pensamos, podem representar uma contribuição significativa para a formação do professor de PLAc. Por fim, teceremos nossos comentários finais, de forma a concluir nossa reflexão.

Passemos então à delimitação da área e à identificação de alguns desafios na formação do professor de PLAc.

\section{Português como língua de "acolhimento" e desafios na formação do professor de PLAc}

Com vistas ao trabalho com pessoas advindas de processos de migração forçada (CLOCHARD, 2007) o termo Português Língua de Acolhimento (PLAc) tem sido amplamente usado em pesquisas concernentes ao ensino de português para os "deslocados forçados". Segundo Diniz e Lopez (2018), a designação deslocados forçados refere-se "tanto [a]os refugiados - termo amplamente utilizado pelo ACNUR ${ }^{3}$ em seus relatórios [...] quanto [a]os demais imigrantes procedentes de diferentes processos de migração de crise, inclusive aqueles que recebem vistos humanitários no Brasil” (DINIZ; LOPEZ, 2018, p. 1). Os autores entendem o PLAc como

a ramificação da subárea de Português como Língua Adicional (PLA) - integrante, portanto, da área de Linguística Aplicada - que se dedica à pesquisa e ao ensino de português para imigrantes, com destaque para deslocados forçados, que estejam em

\footnotetext{
${ }^{3}$ Alto Comissariado das Nações Unidas para Refugiados
} 
situação de vulnerabilidade e que não tenham o português como língua materna. (DINIZ; LOPEZ, 2018, p. 3)

O termo "acolhimento" na expressão Português Língua de Acolhimento tem sido discutido por alguns autores (BIZON; CAMARGO, 2018; DINIZ; NEVES, 2018; LOPEZ, 2016; NEVES, 2018), que indicam ser equivocada a ideia de que o português funciona para todos os imigrantes como uma língua de acolhimento. Segundo Diniz e Neves (2018),

\begin{abstract}
Partir do princípio de que ele [o português] sempre o é - ou pode vir a sê-lo a depender da abordagem, método ou técnicas adotados pelo professor - é apagar os conflitos identitários que podem estar em jogo para alguns sujeitos quando passam a (ter que) se relacionar com o português. Para alguns, por exemplo, esse idioma pode ser, acima de tudo, uma "ferramenta de defesa pessoal" (LOPEZ, 2016). Para outros, talvez, a suposta "língua de acolhimento" possa representar "o risco do exílio" (REVUZ, 2006), na contradição com um desejo de ser e estar apenas na língua materna, no lar de onde nunca se imaginou querer sair um dia. (DINIZ; NEVES, 2018, p. 105)
\end{abstract}

De acordo com Bizon e Camargo (2018), o acolhimento deve ser compreendido como uma perspectiva que não apague as tensões e relações de poder. Nesse sentido, os autores indicam que falar em "língua de acolhimento" pode promover a ideia de que há uma única língua em cena no processo de acolhimento. É neste sentido que os autores propõem, como alternativa à idéia de uma "língua de acolhimento", a perspectiva de um "acolhimento em línguas". Segundo Bizon e Camargo, tal mudança aponta para uma perspectiva de acolhimento em que "as diferenças trazidas pelo outro não sejam apagadas ou vistas como um problema a ser extirpado, mas um recurso legítimo e enriquecedor das práticas linguísticas e dos processos de construção social” (BIZON; CAMARGO, 2018, p. 717).

De nossa parte, gostaríamos de destacar o que há de propriamente discursivo no âmbito do "acolhimento" dos imigrantes forçados. Em consonância com nossa fundamentação teórica, não podemos deixar de indicar que o "acolhimento" é, sempre e inevitavelmente, 
marcado pelo discurso. Os deslocados forçados são (ou devem ser) "acolhidos" com políticas, sem dúvida, mas julgamos ser importante que se atente para os discursos que, no âmbito do ensino e aprendizagem de PLAc, exercem seus efeitos de sentido (PÊCHEUX, 1997). Nossa reflexão acerca da formação de professores de PLAc será feita, portanto, colocando ênfase no "acolhimento" como prática discursiva, prática que sofre necessariamente os efeitos da ideologia (ALHTUSSER, 1998). Nessa perspectiva, assume relevância a indicação que fizemos acima, referente a discursos preconceituosos que atravessam a prática de ensino de PLAc. Conforme indicamos, a existência de tais discursos confronta a formação do professor da área com um desafio.

Retomemos aqui o conceito de discurso da falta, abordado por Diniz e Neves (2018). De acordo com os autores, o discurso da falta corresponde a um

\begin{abstract}
discurso essencialista e totalizador que, a partir de uma posição etnocêntrica, significa certos sujeitos por aquilo que supostamente "não são", "não fazem", "não sabem" e "não conhecem", apagando, consequentemente, suas vivências, suas agências, seus saberes e seus conhecimentos - que, cabe ressaltar, não integram os repertórios daqueles que os enxergam como um conjunto de lacunas a serem preenchidas. Como efeito desse discurso, naturaliza-se a ideia de que tais sujeitos não estão "prontos" para ocuparem os lugares que estão ocupando ou desejam ocupar. (DINIZ; NEVES, 2018, p.100-101)
\end{abstract}

Os autores indicam que além de configurar os sujeitos em função de suas supostas faltas, o discurso da falta, no âmbito do ensino e da aprendizagem de PLAc, naturaliza um determinado imaginário, qual seja, o de que o acesso a certas práticas letradas em português seria garantia de acesso a posições sociais mais valorizadas, funcionando como um instrumento para o sucesso ${ }^{4} 5$. É nessa perspectiva que, segundo Diniz e Neves (2018), o

\footnotetext{
${ }^{4}$ Sobre esse ponto, Diniz (2010) indica que "a aprendizagem do português aparece, em geral, não como um fim per se, mas como um instrumento, um meio para se atingirem outros objetivos" (DINIZ, 2010, p.85).

${ }_{5}$ Ainda acerca desta questão, acreditamos que é possivel associar o imaginário delineado pelos autores à idealização da lingua inglesa como mercadoria que, supostamente, seria garantia de sucesso profissional e de inclusão na sociedade globalizada. A esse respeito, conferir Leite (2009), Gasparini (2009) e Lucena e Torres (2019).
}

Gláuks: Revista de Letras e Artes-jan/jun. 2020 - Vol. 20, $N^{o} 1$ 
discurso da falta se sustenta num modelo "autônomo" de letramento (modelo que é criticado por Brian Street), de acordo com o qual "o letramento, por si só, permitiria a crianças, jovens e adultos 'iletrados' desenvolver-se cognitiva, econômica e socialmente, tornando-se cidadãos melhores" (DINIZ; NEVES, 2018, p. 101). Com isso, ficam obliteradas práticas letradas que não são consideradas como tais em função de um etnocentrismo.

É, portanto, a partir de uma posição etnocêntrica que se qualifica alguns sujeitos a partir de suas supostas faltas. A esse respeito, os autores mencionam que é um lugar comum na área de ensino e aprendizagem de PLAc a menção aos "baixos níveis de letramento" de alguns estudantes estrangeiros. De acordo com Diniz e Neves,

\footnotetext{
No funcionamento do discurso da falta, não há espaço para se levantar a possibilidade de que nossas práticas de ensino e avaliação vão ao encontro daquelas com que estão acostumados discentes de determinadas culturas, mas não de outras, o que poderia explicar algumas diferenças de rendimento eventualmente observáveis entre estudantes de diferentes origens (DINIZ; NEVES, 2018, p. 103)
}

Diniz e Neves (2018) indicam também que, em casos extremos, o baixo rendimento escolar pode ser abordado como uma patologia, inclusive com encaminhamento a unidades de saúde para avaliação médica e psicológica. Os autores concluem reafirmando a importância de um sistema escolar que não se isente de suas responsabilidades, delegando-as a profissionais da saúde, e que prepare professores e profissionais da educação para o trabalho com PLAc. Ademais, mencionam "a necessidade imperativa de políticas linguísticas direcionadas a discentes cuja língua materna não é o português" (DINIZ; NEVES, 2018, p. 90).

As ponderações de Lopez (2018) dialogam com a argumentação de Diniz e Neves sobre o discurso da falta. A autora denuncia o que considera ser, no âmbito do ensino e da aprendizagem de PLAc, um discurso segundo o qual a língua portuguesa configura-se como uma obrigação aos deslocados forçados, sendo a eles imposta. Tal imposição é vista pela autora como uma violência simbólica que pode contribuir para a segregação dos imigrantes:

Gláuks: Revista de Letras e Artes-jan/jun. 2020 - Vol. 20, $N^{o} 1$ 


\section{GLÁUKS}

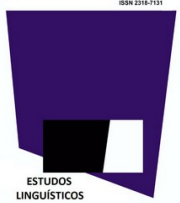

"o discurso da obrigatoriedade da aprendizagem do português, muitas vezes ocultado por um discurso que apenas sugere a necessidade de tal aprendizagem, é, de certa forma, opressor" (LOPEZ, 2018, p. 28). Lopes obviamente não nega a relevância da aprendizagem da língua portuguesa por parte dos imigrantes. Contudo, a autora indica que talvez a língua não seja o único ativo que os deslocados forçados necessitam: "por isso há a necessidade de políticas públicas adequadas para a recepção e para o auxílio a esses indivíduos” (LOPEZ, 2018, p. 30). Um dos problemas com o discurso denunciado por Lopez é justamente o apagamento de tal necessidade.

As discussões realizadas por Diniz e Neves (2018) e por Lopez (2018) apontam para a possibilidade de que, seja pela via do discurso da falta (em que o imigrante é significado a partir de suas falhas de letramento), seja através do discurso da obrigatoriedade da aprendizagem do português (com os efeitos de silenciamento dele decorrentes), haja um esmagamento do imigrante: utilizamos aqui o termo usado por Orlandi (1996) em sua reflexão acerca do discurso pedagógico, que coloca em funcionamento um "esmagamento do outro" (ORLANDI, 1996, p. 17). Retomaremos tal conceito adiante.

$\mathrm{Na}$ argumentação que desenvolvemos neste artigo, torna-se relevante o conceito de decolonialidade em sua articulação com o ensino de línguas. Retomando trabalhos realizados no âmbito dos estudos decoloniais, Pardo (2019) indica que o conceito de decolonialidade contribui para descontruir a ideia de que, com o fim das administrações coloniais e o advento das nações na periferia, vivemos em um mundo pós-colonial, descolonizado. De acordo com Pardo (2019),

as relações desiguais de poder e a hierarquização sociocultural, político-econômica, étnico-racial e de gênero/sexualidade de diferentes grupos, por meio de classificações binárias, tais como desenvolvido/subdesenvolvido, superior/inferior, civilizados/bárbaros, centro/periferia, inauguradas durante o período colonial, não se encerraram com o fim do colonialismo. (PARDO, 2019, p. 209)

Gláuks: Revista de Letras e Artes-jan/jun. 2020 - Vol. 20, $N^{o} 1$ 


\section{GLÁUKS}

Apontando para o fato de que a colonização territorial e administrativa cede lugar à colonialidade, o autor indica que os estudos acerca da decolonialidade buscam romper paradigmas cristalizados nas relações socioculturais, político-econômicas, étnico-raciais e de gênero/sexualidade. Gostaríamos de destacar a menção feita por Pardo, na citação acima, a "relações desiguais de poder" e a uma "hierarquização étnico-racial por meio de classificações binárias". A indicação do autor parece-nos relevante para refletir sobre relações que se desdobram no âmbito do ensino e da aprendizagem de português para deslocados forçados. Ora, as discussões acerca do discurso da falta (DINIZ; NEVES, 2018) e do discurso da obrigatoriedade da aprendizagem do português (LOPEZ, 2018) apontam, justamente, para a existência, no ensino e na aprendizagem de PLAc, de "relações desiguais de poder" e de uma "hierarquização étnico-racial por meio de classificações binárias" (PARDO, 2019). Apontam, portanto, para a pertinência dos estudos sobre a decolonialidade para a área de PLAc e para a formação do professor.

Refletindo acerca da decolonialidade e o ensino de língua inglesa, Pardo (2019) argumenta a favor de um "posicionamento crítico" em relação aos objetivos estipulados acerca do ensino do idioma, fazendo com que os saberes específicos dos sujeitos envolvidos neste processo sejam levados em consideração, "bem como seus contextos, seus corpos, sua cultura, sua linguagem e seus conhecimentos de mundo para que possam desenvolver o olhar crítico acerca da construção do conhecimento e das relações de poder desiguais envolvidas neste processo" (PARDO, 2019, p. 219). Embora Pardo esteja discutindo a decolonialidade em relação ao ensino de língua inglesa, pensamos que suas considerações possuem relevância para o ensino e a aprendizagem de PLAc.

Acreditamos que elementos da teorização da Análise do Discurso possam contribuir para o "posicionamento crítico", para o "olhar crítico" mencionado por Pardo (2019). Em outras palavras, tais elementos podem contribuir para a decolonialidade no âmbito da formação do professor de PLAc. É o que abordaremos na próxima seção.

\section{Gláuks: Revista de Letras e Artes-jan/jun. 2020 - Vol. 20, $N^{o} 1$}




\section{Formações imaginárias, discurso pedagógico e formação de professores de PLAc}

O discurso é definido por Michel Pêcheux como efeito de sentidos entre locutores (PÊCHEUX, 1997). Fundamental aqui é a ideia de que o discurso não corresponde a uma "transmissão de sentidos" ou a uma "comunicação", mas sim a um efeito de sentidos que se produz no ato de tomada da palavra. Ato que se realiza a partir de um determinado lugar no jogo de relações sociais. É, pois, esse jogo de lugares que determina os efeitos de sentido: falar de um determinado lugar, para alguém situado também em um lugar, eis o que preside o funcionamento do discurso.

Contudo, o jogo de lugares que preside o discurso, compondo suas condições de produção, não é simplesmente externo a ele. Tais lugares encontram-se representados no âmbito dos processos discursivos. É nessa perspectiva que Pêcheux (1997) aborda os lugares sociais em termos de formações imaginárias:

\footnotetext{
Nossa hipótese é a de que esses lugares estão representados nos processos discursivos em que são colocados em jogo. Entretanto, seria ingênuo supor que $o$ lugar como feixe de traços objetivos funciona com tal no interior do processo discursivo; ele se encontra aí representado, isto é, presente, mas transformado; em outros termos, o que funciona nos processos discursivos é uma série de formações imaginárias que designam o lugar que A e B se atribuem cada um a si e ao outro, a imagem que eles se fazem de seu próprio lugar e do lugar do outro. (PÊCHEUX, 1997 , p. 82 , grifos do autor)
}

Reproduziremos aqui o quadro elaborado por Pêcheux (1997) para representar as formações imaginárias, formações que compõem as condições de produção do discurso:

Gláuks: Revista de Letras e Artes-jan/jun. 2020 - Vol. 20, $N^{o} 1$ 


\begin{tabular}{|c|c|c|c|}
\hline & $\begin{array}{c}\text { Expressão que } \\
\text { designa as formações } \\
\text { imaginárias }\end{array}$ & Significação da expressão & $\begin{array}{l}\text { Questão implícita cuja } \\
\text { "resposta" subentende a } \\
\text { formação imaginária } \\
\text { correspondente }\end{array}$ \\
\hline \multirow{2}{*}{$\mathbf{A}$} & $\mathbf{I}_{\mathrm{A}}{ }^{(\mathbf{A})}$ & $\begin{array}{c}\text { imagem do lugar de } A \text { para } 0 \\
\text { sujeito colocado em } A\end{array}$ & $\begin{array}{c}\text { "Quem sou eu para the falar } \\
\text { assim?" }\end{array}$ \\
\hline & $\mathbf{I}_{A}{ }^{(\mathbf{B})}$ & $\begin{array}{l}\text { imagem do lugar de } B \text { para o } \\
\text { sujeito colocado em } A\end{array}$ & $\begin{array}{c}\text { "Quem é ele para que eu lhe } \\
\text { fale assim?" }\end{array}$ \\
\hline \multirow{2}{*}{ B } & $\mathbf{I}_{\mathrm{B}}{ }^{(\mathbf{B})}$ & $\begin{array}{l}\text { imagem do lugar de } B \text { para o } \\
\text { sujeito colocado em B }\end{array}$ & $\begin{array}{c}\text { "Quem sou eu para que ele } \\
\text { me fale assim?" }\end{array}$ \\
\hline & $\mathbf{I}_{\mathbf{B}}{ }^{(\boldsymbol{A})}$ & $\begin{array}{l}\text { imagem do lugar de A para o } \\
\text { sujeito colocado em B }\end{array}$ & $\begin{array}{c}\text { "Quem é ele para que me } \\
\text { fale assim?" }\end{array}$ \\
\hline
\end{tabular}

Abordar os lugares sociais em termos de um jogo de imagens, isto é, em termos da imagem que os interlocutores fazem de seu próprio lugar e do lugar do outro, traz um elemento essencial para a discussão aqui realizada: enquanto imagens ou representações com existência no âmbito do processo discursivo, tais elementos podem sofrer as vicissitudes do jogo discursivo: para além da reprodução, a transformação. Retomaremos esse ponto posteriormente.

Por ora, resta indicar que a caracterização das formações imaginárias assim como feita por Pêcheux no texto sobre o qual nos debruçamos - Análise Automática do Discurso, de 1969 - pode dar margem a um entendimento psicossociológico das condições de produção, conforme indica Courtine (2014). Segundo o autor, a definição elaborada por Pêcheux em 1969 não rompe com as origens psicossociológicas do conceito: “Os termos de 'imagem' ou de 'formação imaginária' poderiam perfeitamente substituir a noção de 'papel', tal como aquela utilizada nas 'teorias do papel', herdadas da sociologia funcionalista [...] ou ainda do interacionismo psicológico [...]" (COURTINE, 2014, p. 50). A respeito da crítica feita por Courtine, poderíamos acrescentar que as próprias questões implícitas às formações imaginárias, no quadro acima - “quem sou eu para lhe falar assim?”, “quem é ele para que eu lhe fale assim?" -, podem dar margem ao entendimento equivocado de que as imagens se

Gláuks: Revista de Letras e Artes-jan/jun. 2020 - Vol. 20, $N^{o} 1$ 


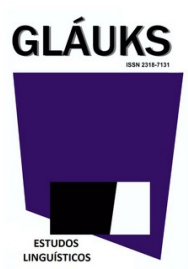

reduzem à consciência que o sujeito tem delas, o que seria negar que as imagens exercem efeitos a despeito da consciência do sujeito.

O ponto importante aqui é que, em nossa leitura, o jogo de imagens de que fala Pêcheux em 1969 deve ser lido à luz das considerações de Louis Althusser (1998) sobre a ideologia, considerações que exerceram efeito importante ao longo da trajetória teórica de Pêcheux, e que se encontram ausentes do texto de $1969^{6}$. Segundo Althusser, a ideologia interpela o indivíduo em sujeito, o que implica em levar em conta um duplo aspecto da interpelação: ao mesmo tempo em que a ideologia determina o dizer e o fazer do sujeito em consonância com o lugar por ele ocupado no jogo de relações sociais, ela engendra também, inevitavelmente, o engodo da liberdade e da autonomia, como se o sujeito fosse dono e senhor do que diz e faz. Ao mesmo tempo em que a ideologia determina, ela apaga o exercício desta determinação através de um efeito ilusório de liberdade.

Portanto, considerar o lugar social enquanto imagem ou representação, como o faz Pêcheux em 1969, implica em levar em conta que tal imagem ou representação exerce efeitos no dizer e no fazer do sujeito para além de sua consciência ou intenção. Trata-se, portanto, de um lugar social que interpela o sujeito, determinando-o e, ao mesmo tempo, produzindo a ilusão da autonomia. Tais considerações não deixam de ter relação com nossa discussão acerca da formação do professor de PLAc: o jogo de imagens que preside a prática discursiva no processo de ensino e aprendizagem de PLAc exerce efeitos nos sujeitos nela envolvidos apesar de suas "boas intenções"... ganham relevância aqui as considerações sobre o discurso da falta (DINIZ; NEVES, 2018) e sobre o discurso da obrigatoriedade da aprendizagem de português (LOPEZ, 2018), que exercem seus efeitos de sentido através da ilusão da liberdade. Retomaremos este ponto adiante.

Para os nossos propósitos neste artigo, importa retomar o conceito de discurso pedagógico elaborado por Orlandi (1996). Retomando o jogo de imagens assim como elaborado por Pêcheux (1997), Orlandi apresenta o esquema do discurso pedagógico:

\footnotetext{
${ }^{6}$ Sobre tal ausência, conferir Henry (1997).
}

Gláuks: Revista de Letras e Artes-jan/jun. 2020 - Vol. 20, $N^{o} 1$ 


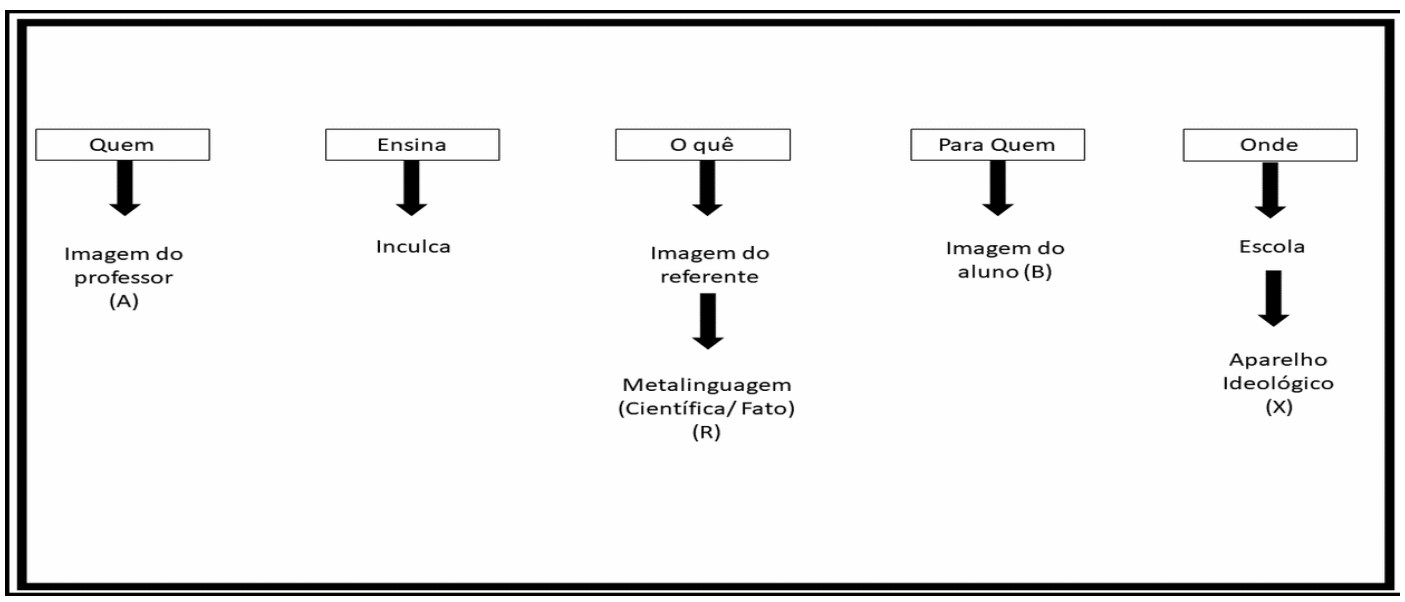

Segundo Orlandi, o esquema pode ser representado assim:

A ensina $\mathrm{R}$ a B em X (aparelho ideológico)

Interessa destacar do esquema proposto por Orlandi que A e B, em consonância com as formulações de Pêcheux (1997), correspondem a imagens, imagem do professor e imagem do aluno: "O aluno é idealmente $\mathrm{B}$, isto é, a imagem social do aluno (o que não sabe e está na escola para aprender), e o professor é idealmente A, isto é, a imagem social do professor (aquele que possui o saber e está na escola para ensinar)" (ORLANDI, 1996, p. 21). A partir de tais imagens, é possível entender a indicação da autora de que, no discurso pedagógico, o ensino toma a forma da inculcação (ensinar = inculcar) e de um "esmagamento do outro":

parece-nos que, enquanto discurso autoritário, o DP [discurso pedagógico] aparece como discurso do poder, isto é, como em R. Barthes, o discurso que cria a noção de erro e, portanto, o sentimento de culpa, falando, nesse discurso, uma voz segura e auto-suficiente. A estratégia, a posição final, aparece como o esmagamento do outro. Nesse sentido, poderíamos dizer que $A$ ensina $B=A$ influencia $B$. (ORLANDI, 1996, p. 17, grifos da autora)

Gláuks: Revista de Letras e Artes-jan/jun. 2020 - Vol. 20, $N^{o} 1$ 
Nesta citação, vê-se a menção ao discurso pedagógico como um discurso autoritário, em consonância com a tipologia proposta por Orlandi (1996), que distingue três tipos de discurso: autoritário, polêmico e lúdico. Sobre o discurso autoritário, a autora afirma que nele não há interlocutores, mas um agente exclusivo. Pode-se entender esse ponto se levamos em conta as imagens de aluno e professor no discurso pedagógico: o professor ensina, o aluno aprende. É nesse sentido que, como discurso autoritário, o discurso pedagógico não dá lugar a uma reversibilidade de lugares, o professor despontando como agente único.

A partir do esquema do discurso pedagógico, reproduzido acima, Orlandi (1996) indica que a estratégia básica do discurso pedagógico deveria ser uma pergunta em relação àquilo que se ensina (o referente, no esquema). Porém, a autora indica que o jogo de imagens que preside o discurso pedagógico impede uma reflexão sobre o referente; em seu lugar, desponta o "é porque é”, na forma de definições rígidas e conclusões exclusivas e dirigidas. Eis, portanto, o que está em jogo no esmagamento do outro no âmbito do discurso pedagógico: um silenciamento do aluno, o impedimento à reflexão a partir do qual o professor desponta como agente único, transmissão unilateral de um conteúdo já pronto sobre o referente. Desponta daí uma "função tranquilizante" no âmbito do discurso pedagógico: "não há sustos, dúvidas ou questões sem resposta” (ORLANDI, 1996, p. 30).

A discussão feita por Orlandi pode ser relevante para uma reflexão sobre o PLAc e a formação de professores na área ${ }^{7}$. A esse respeito, a discussão acerca do discurso da falta (DINIZ; NEVES, 2018) e do discurso da obrigatoriedade da aprendizagem do português (LOPEZ, 2018) revela, como indicamos acima, um verdadeiro esmagamento daquele que aprende PLAc. É também um jogo de imagens que preside ambos os discursos. No caso do discurso da falta, conforme Diniz e Neves (2018), teríamos determinadas imagens do professor e do aluno: o professor como aquele que possui um saber sobre a língua portuguesa e está ali para ensinar, e o aluno como aquele que não sabe, não é, não faz, não conhece, e

\footnotetext{
${ }^{7}$ Embora haja, na argumentação de Orlandi (1996), uma vinculação estreita entre a instituição escolar e o discurso pedagógico (conferir esquema acima), acreditamos que seus efeitos de sentido não se restrinjam à escola, despontando a possibilidade de que o jogo de imagens constitutivo do discurso pedagógico exerça seus efeitos de sentido em práticas pedagógicas que não ocorrem na instituição escolar.
}

Gláuks: Revista de Letras e Artes-jan/jun. 2020 - Vol. 20, $N^{o} 1$ 


\section{GLÁUKS}

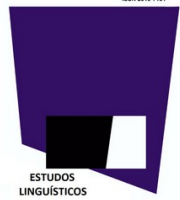

está ali para aprender. Nesse caso, o esmagamento do outro se faz pela via de uma desconsideração das práticas letradas do aprendiz em função de um etnocentrismo (cf. DINIZ; NEVES, 2018). A língua portuguesa, como aquilo que é ensinado (referente), desponta na condição de garantia de acesso a posições sociais mais valorizadas, funcionando como um instrumento para o sucesso (DINIZ, 2010). No caso do discurso da obrigatoriedade da aprendizagem do português, conforme Lopez (2018), teríamos o professor como aquele que possui um saber sobre a língua portuguesa e está ali para impô-la, ao passo que o aluno desponta, como imagem, na condição daquele que não possui tal saber mas deve possuí-lo. $\mathrm{O}$ esmagamento se faz pela via da imposição, da opressão e da segregação.

Em ambos os casos, o esmagamento se faz pela via do discurso, presidido que é pelo jogo de imagens de professor e aluno. E, vale lembrar, trata-se de imagens que interpelam o sujeito, determinando-o e, ao mesmo tempo, engendrando a ilusão da não determinação: interpelados pelos discursos da falta e da obrigatoriedade da aprendizagem do português, professor e alunos despontam, em função de um efeito engendrado pela própria interpelação (ALTHUSSER, 1998), como donos de seus dizeres e fazeres. Cabe então a pergunta: qual poderia ser o posicionamento crítico que promoveria ruptura em relação a tais efeitos? Como promover o posicionamento e o olhar críticos mencionados por Pardo (2019), de forma a decolonizar o ensino e a aprendizagem de PLAc?

Conforme Orlandi (1996) indica, o discurso pedagógico é um discurso autoritário, mas existe a possibilidade da crítica e de que algo escape. É nesse sentido que a autora faz sua proposta, proposta que, em nossa leitura, pode representar uma contribuição significativa para a formação de professores de PLAc. Para Orlandi, uma posição crítica seria fazer do discurso pedagógico um discurso polêmico. Se o discurso autoritário é caracterizado por uma ausência de interlocução, despontando um agente único, o discurso polêmico é caracterizado por uma “dinâmica de papéis" (ORLANDI, 1996, p. 34). É nessa perspectiva que Orlandi faz a sua proposta tanto no que se refere ao professor quanto no que concerne ao aluno:

Gláuks: Revista de Letras e Artes-jan/jun. 2020 - Vol. 20, $N^{o} 1$ 
Do ponto de vista do autor (professor) uma maneira de se colocar de forma polêmica é construir seu texto, seu discurso, de maneira a expor-se a efeitos de sentidos possíveis, é deixar um espaço para a existência do ouvinte como "sujeito". Isto é, deixar vago um espaço para o outro (o ouvinte) dentro do discurso e construir a própria possibilidade de ele mesmo (locutor) se colocar como ouvinte. É saber ser ouvinte do próprio texto e do outro.

Da parte do aluno, uma maneira de instaurar o polêmico é o exercer sua capacidade de discordância, isto é, não aceitar aquilo que o texto propõe e o garante em seu valor social: é a capacidade do aluno de se constituir ouvinte e se construir como autor na dinâmica da interlocução, recusando tanto a fixidez do dito como a fixação do seu lugar como ouvinte. Ou seja, é próprio do discurso autoritário fixar o ouvinte na posição de ouvinte e o locutor na posição de locutor. Negar isso não é negar a possibilidade de ser ouvinte, é não aceitar a estagnação nesse papel, nessa posição. (ORLANDI, 1996, p. 32-33)

Portanto, ante a fixidez do dito no discurso pedagógico, a autora sugere a exposição a efeitos de sentidos possíveis e o exercício da capacidade de discordância por parte do aluno. Diante da fixação dos lugares do locutor e do ouvinte, propõe-se uma dinâmica na interlocução. Segundo Orlandi, essa dinâmica de papéis promoveria uma recuperação do objeto de reflexão e uma produção de conhecimento mais conflituosa.

A proposta encaminhada por Orlandi (1996) pode ser relevante para a formação de professores de PLAc uma vez que se leva em conta a existência do discurso da falta (DINIZ; NEVES, 2018) e do discurso da obrigatoriedade da aprendizagem do português (LOPEZ, 2018). A dinâmica de papéis proposta por Orlandi pode exercer deslocamentos significativos em ambos os discursos. Na medida em que a relação se faz mais conflituosa, com a possibilidade de reversibilidade de lugares, reflexão e discordância por parte do aluno, este pode se significar / ser significado por aquilo que é, que faz, que sabe e que conhece, por contraponto à sua significação, no âmbito do discurso da falta, a partir do que "não é", "não faz", "não sabe” e "não conhece" (cf. DINIZ; NEVES, 2018). Da mesma forma, o conflito, a dinâmica de lugares, a reflexão e a discordância em relação ao mestre pode viabilizar, no âmbito da aprendizagem do PLAc, uma relação que seja menos opressora e segregadora (cf. LOPEZ, 2018) e na qual não se desconsidera o sujeito e a(s) língua(s) que o constituem, relação na qual a língua portuguesa desponta não como uma obrigação ou uma imposição,

$$
\text { Gláuks: Revista de Letras e Artes-jan/jun. } 2020 \text { - Vol. 20, } N^{o} 1
$$


mas como elemento que pode viabilizar processos de territorialização que não sejam precários (BIZON, 2018).

Em nossa retomada das formações imaginárias assim como discutidas por Pêcheux (1997), indicamos que o autor aborda os lugares sociais em termos de um jogo de imagens, isto é, em termos da imagem que os interlocutores fazem de seu próprio lugar e do lugar do outro. Indicamos também que abordar os lugares sociais como imagens traz consequências importantes, uma vez que, de acordo com Pêcheux, tais imagens não são exteriores ao discurso, elas têm existência no próprio processo discursivo. Portanto, tais elementos podem sofrer as vicissitudes do jogo discursivo, o que aponta para a possibilidade da transformação, para além da reprodução: a própria prática discursiva pode exercer efeitos nas imagens cristalizadas socialmente. Em outras palavras, o encaminhamento proposto por Orlandi (1996), com o potencial de produzir transformações nas práticas discursivas que tomam lugar no processo de ensino e aprendizagem de PLAc, pode igualmente produzir mudanças significativas nas imagens socialmente cristalizadas do professor e do aluno que estão às voltas com o ensino e a aprendizagem de PLAc.

É nesta direção que entendemos que a teorização sobre as formações imaginárias (PÊCHEUX, 1997) e sobre o discurso pedagógico (ORLANDI, 1996) pode representar uma contribuição importante para a formação de professores de PLAc. Estes elementos teóricos permitem abordar o processo de ensino e aprendizagem de PLAc em termos de sua configuração discursiva e, a partir disso, propor encaminhamentos que, levando em conta tal configuração, permitem resistir a discursos preconceituosos no âmbito do ensino e da aprendizagem de PLAc, contribuindo assim para mudanças significativas tanto na prática (discursiva) de ensino de PLAc quanto nas imagens sociais de professor e alunos.

Em sua reflexão acerca da decolonialidade e o ensino de língua inglesa, Pardo (2019) argumenta a favor de um "posicionamento crítico", como vimos. Trata-se, para o autor, de fazer com que os saberes específicos dos sujeitos envolvidos sejam levados em consideração. A proposta feita por Orlandi (1996) em relação ao discurso pedagógico pode contribuir, em

Gláuks: Revista de Letras e Artes-jan/jun. 2020 - Vol. 20, $N^{o} 1$ 


\section{GLÁUKS}

nossa leitura, para o posicionamento crítico mencionado por Pardo (2019). Tal proposta refere-se, justamente, a levar em conta os saberes específicos dos sujeitos envolvidos no trabalho com línguas. Nesse sentido, o encaminhamento realizado por Orlandi (1996) pode representar uma contribuição significativa para a decolonialidade no ensino de línguas e na formação do professor de PLAc.

Passemos agora aos nossos comentários conclusivos.

\section{Considerações finais}

Conforme indicamos nas linhas iniciais deste ensaio, a chamada para publicação neste número da Glauks, com foco em "Perspectivas críticas e decoloniais na formação de professores de línguas: avanços e desafios", mobilizou-nos em uma tentativa de abordar uma questão: uma vez que tomamos a Análise do Discurso como fundamento, o que poderia se configurar como um posicionamento "crítico" e "decolonial" na formação de professores de português como língua de acolhimento?

Em consonância com nossos pressupostos teóricos, de acordo com os quais o discurso é efeito de sentido entre locutores (PÊCHEUX, 1997), acreditamos que a possibilidade de ser "crítico" e "decolonial" na formação de professores de PLAc está na dependência de colocar em destaque o que há de propriamente discursivo no "acolhimento" dos deslocados forçados no âmbito do ensino e da aprendizagem de PLAc . Trata-se, para nós, de abordar o processo de ensino e aprendizagem de PLAc como uma prática discursiva, isto é, como uma prática de produção linguageira que se faz a partir de determinados lugares no jogo de relações sociais, conforme indicamos a partir de Pêcheux (1997).

Colocar em destaque a dimensão discursiva do "acolhimento" foi o que possibilitou considerar o jogo de imagens que condiciona o processo de ensino e aprendizagem de PLAc.

Gláuks: Revista de Letras e Artes-jan/jun. 2020 - Vol. 20, $N^{o} 1$ 


\section{GLÁUKS}

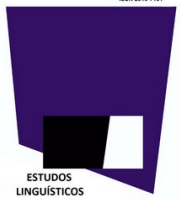

Recorremos ao conceito de discurso pedagógico (ORLANDI, 1996) para abordar o jogo de imagens que, em nossa leitura, pode exercer efeitos neste processo. Abordamos o discurso da falta (DINIZ; NEVES, 2018) e o discurso da obrigatoriedade da aprendizagem do português (LOPEZ, 2018) e identificamos, em consonância com a elaboração de Orlandi (1996), o esmagamento do deslocado forçado que é operado no âmbito de tais discursos.

Discutimos em seguida a possibilidade da crítica, de um posicionamento crítico que possa promover deslocamentos significativos em relação às injunções destes discursos, em função dos quais se engendra, a partir de uma posição etnocêntrica, opressão e segregação dos imigrantes. Segundo pensamos, o encaminhamento proposto por Orlandi (1996), a partir do qual se instaura a possibilidade do conflito, da reversibilidade de lugares e da discordância por parte do aluno, pode representar uma contribuição significativa para a desconstrução da "narrativa colonial" (SOUZA SANTOS, 2002) ${ }^{8}$ no âmbito do ensino e da aprendizagem de PLAc, com consequências importantes para a formação do professor na área.

\section{Referências Bibliográficas}

ALTHUSSER, L. Ideologia e aparelhos ideológicos de Estado. Lisboa: Editorial Presença/ Martins Fontes, 1998.

AMADO, R. S. O ensino de português como língua de acolhimento para refugiados. Revista da Sociedade Internacional de Português Língua Estrangeira. Brasília: 2013. Revista SIPLE Sociedade Internacional de Português Língua Estrangeira, v.7. Fac 2. 2014, s.p. Disponível em:https://www.researchgate.net/publication/272394920_O_ensino_de_portugues_como_ling ua_de_acolhimento_para_refugiados. Acesso em 27 abr. 2020.

ANUNCIAÇÃO, R.F.M. A língua que acolhe pode silenciar? Reflexões sobre o conceito de "Português como Língua de Acolhimento". Revista X. Curitiba. v. 13. n.1.p.35-56, 2018. Disponível em: https://revistas.ufpr.br/revistax/article/view/60341. Acesso em 29 abr. 2020.

\footnotetext{
${ }^{8}$ Segundo Souza Santos (2002), o pós-colonialismo compreende práticas e discursos que desconstroem a narrativa colonial assim como escrita pelo colonizador, tentando substitui-la por narrativas escritas do ponto de vista do colonizado.
} 


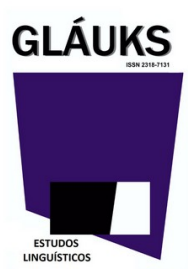

AYDOS, M. R. Migração forçada: uma abordagem conceitual a partir da imigração de angolanos para os estados do Rio de Janeiro e São Paulo, Brasil (1970-2006). 2010. 180.Dissertação (Mestrado em Demografia). Instituto de Filosofia e Ciências Humanas, Universidade de Campinas: Unicamp.

BIZON, A. C. C. Vozes do Programa emergencial 'Pró-Haiti': Narrativas de racialização do 'ser haitiano'. In: BIZON \& DINIZ (orgs.). Dossiê Especial: Português como Língua Adicional em contextos de minorias: (co)construindo sentidos a partir das margens. v. 13. Fac.1. Revista X: Curitiba, 2018. p.57-86. Disponível em: https://revistas.ufpr.br/revistax/article/download/61201/36648. Acesso em 29 abr.2020.

BIZON, A. C. C.; CAMARGO, H. R. E. "Acolhimento e ensino da língua portuguesa à população oriunda de migração de crise no município de São Paulo: Por uma política do atravessamento entre verticalidades e horizontalidades". In: BAENINGER et al (orgs.). Migrações Sul-Sul. Campinas, SP: NEPO/UNICAMP, 2018.

CLOCHARD, O. Les réfugiés dans le monde entre protection et illégalité. In: EchoGéo (online), Fac. 2, 2007. Disponível em: https://doi.org/10.4000/echogeo.1696 . Acesso em 27 abr. 2020.

COURTINE, J. J. Análise do discurso político: o discurso comunista endereçado aos cristãos. São Carlos, SP: EDUFSCar, 2014.

DINIZ, L. R. A. Mercado de línguas: a instrumentalização brasileira do português como língua estrangeira. Campinas: Editora RG, 2010.

DINIZ, L. R. A.; NEVES, A. O. Políticas linguísticas de (in)visibilização de estudantes imigrantes e refugiados no ensino básico brasileiro. Revista X. Curitiba.v. 13. Fac.1. p. 87110, 2018. Disponível em: https://revistas.ufpr.br/revistax/article/download/61225/36629. Acesso em 15 abr. 2020.

GASPARINI, E. N. Língua Inglesa e Ideologia. Solta a voz. Goiânia, v. 20, n. 1, p. 1-12, 2009.

Gláuks: Revista de Letras e Artes-jan/jun. 2020 - Vol. 20, $N^{o} 1$ 


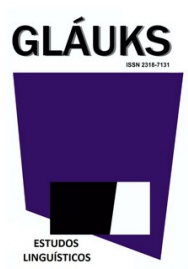

LEITE, P.M.C.C. Yes, Vamos Correr para "Dominar" a Língua: Como a língua Inglesa é Representada em Dois Textos da Revista Veja. 2013. 247. Dissertação (Mestrado em Letras). Universidade Federal de São João del-Rei: São João del-Rei.

LIMA, H.H; VIANINI, C. Gêneros orais do contexto acadêmico no ensino de português como língua adicional: desenvolvimento de material didático. Revista Olhares e Trilhas [recurso eletrônico]. Uberlândia, v.21. Fac 03. p.407-427, 2019. Disponível em https://doi.org/10.14393/OT2019v21.n.3.45348. Acesso em 27 abr. 2020.

LOPEZ, A. P. de A. Subsídios para o planejamento de cursos de português como língua de acolhimento para imigrantes deslocados forçados no Brasil. 2016. 261fl. Dissertação (Mestrado em Linguística Aplicada). Universidade Federal de Minas Gerais, Belo Horizonte.

LOPEZ, A.P.A; DINIZ, L. R. A. Iniciativas Jurídicas e Acadêmicas para o Acolhimento no Brasil de Deslocados Forçados. Brasília, v.9. Fac 9. p. 16-28, 2018. Disponível em: https://www.researchgate.net/publication/330635043_Iniciativas_Juridicas_e_Academicas_Br asileiras_para_o_Acolhimento_de_Imigrantes_Deslocados_Forcados. Acesso em 27 abr. 2020 .

LUCENA, M.I.P; TORRES, A.C.G. Ideologia monolíngue, mercantilização e instrumentalização da língua inglesa na alteração da LDB em 2017 e em anúncios publicitários de cursos livres. Revista Brasileira de Linguística Aplicada. Belo Horizonte. v.19. Fac.03. p.635-654, 2019. Disponível em: https://doi.org/10.1590/1984-6398201914230. Acesso em 23 abr. 2020.

NEVES, A. O. Política Linguística de Acolhimento a Crianças imigrantes no Ensino Fundamental Brasileiro: um estudo de caso.2018. 185 fls. Dissertação (Mestrado em Linguística Aplicada). Universidade Federal de Minas Gerais, Belo Horizonte.

PARDO, Fernando da Silva. Decolonialidade e ensino de línguas: perspectivas e desafios para a construção do conhecimento corporificado. Revista Letras Raras. Campina Grande, v. 8, Fac. 3, p. Port. 200-221 / Eng. 198-218, 2019. Disponível em: http://dx.doi.org/10.35572/rlr.v8i3.1422. Acesso em 27 abr. 2020.

Gláuks: Revista de Letras e Artes-jan/jun. 2020 - Vol. 20, $N^{o} 1$ 
PÊCHEUX, M. Análise Automática do Discurso. In: GADET, F. e T. HAK (Org.). Por uma análise automática do discurso - uma introdução à obra de Michel Pêcheux. Tradução de Bethania S. Mariani et al. Campinas: UNICAMP, 1997.

SÃO BERNARDO, M. A. de. Português como língua de acolhimento: um estudo com imigrantes e refugiados no Brasil. 2016. 206 fls. Tese (Doutorado em Linguística). Universidade Federal de São Carlos, São Carlos.

SOUSA SANTOS, B. Between Prospero and Caliban: colonialism, postcolonialism and inter-identity. Luso-Brazilian Review, Madison, v. 39, n. 2, p. 9-43, win. 2002.

ZAMBRANO, C. H. G. Português Como Língua de Acolhimento em Roraima: da Falta de Formação Específica à Necessidade Social. Revista X. Curitiba v.14. Fac.3. p.16-32, 2019. Disponível em: https://revistas.ufpr.br/revistax/article/view/60942/39021. Acesso em 15 abr. 2020.

\title{
Discourse analysis and portuguese as a welcoming language teacher development
}

\begin{abstract}
In this essay we discuss theoretical elements from Discourse Analysis that may contribute to a critical and decolonial perspective in Portuguese as a Welcoming Language (PWLg) teacher development. We aimed at highlighting the discursive dimension of the "welcoming" of forced displaced immigrants in PWLg's teaching and learning and, in accordance with this perspective, we discussed the discourse of lack (DINIZ; NEVES, 2018) and the discourse of obligation of Portuguese learning (LOPEZ, 2018). We could identify, in both discourses, the effects of meaning of pedagogical discourse (ORLANDI, 1996), within which there is a "massacre of the other" due to teacher and student's socially crystallized images. We identified the possibility of resistance and displacement in relation to the aforementioned discourses once, as opposed to the pedagogical discourse, there is promotion of a more conflictual relation between PWLg teacher and student, in which the student can have the floor and exert his / her disagreement. This possibility of resistance and displacement, conceived by means of theoretical elements from Discourse Analysis, may contribute to decoloniality in PWLg teacher training.
\end{abstract}

Gláuks: Revista de Letras e Artes-jan/jun. 2020 -Vol. 20, $N^{o} 1$ 


\section{GLÁUKS}

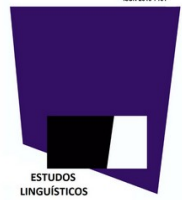

Keywords: Portuguese as a Welcoming Language, teacher development, discourse analysis, decoloniality. 